\title{
The Regional Secure Units Programme: A Personal Appraisal*
}

\author{
The Present State of Play and Future Plans
}

\author{
Peter R. Snowden, Senior Registrar in Forensic Psychiatry, Park Lane Hospital and Merseyside Forensic Psychiatry \\ Service
}

Since central government allocated capital and revenue money for the regional secure units (RSU) programme, following the 1975 Butler Report, the planning and building programme has been gathering momentum. It was felt it would be useful to review the present complicated and varied picture and to look ahead to the future. This seems a particularly apt moment to look around the regions as the climate of opinion, both within the clinical professions and in the various NHS administrative levels, is changing. Reference will mostly be made to the provisions for Mental Illness rather than for Mental Impairment and Adolescents.

\section{The current position in England and Wales}

Wales and Oxford are now well behind the other Regions. Neither has a forensic psychiatrist to pursue the cause. The Welsh Office is at present looking at the possibility of building secure units almost eight years after the Butler recommendations. Currently there is a locked intensive care (but not forensic) unit in Denbigh Hospital and an open, but isolated, 19-bed forensic unit in Garth Angharad Hospital, run by a general psychiatrist with a forensic interest.

Oxford, on the basis of a regional survey, decided that there was no need for an RSU. However, they have approached nearby Trent Region to discuss the feasibility of using some of the Trent RSU beds for Oxford Region patients, somewhat weakening their case.

Four Regions did not appoint forensic psychiatrists until late in the day, did not have specialist advice and have run into problems. Northern Region is the only one to have patients in an RSU. The unit opened in November, 1980 at St Lukes Hospital, Middlesbrough. It is small in size and there are design difficulties (such as limited occupational space) which may require further capital investment. Staffing is a major problem, especially nurse recruitment, and as a result only 20 of the 30 beds are in operation.

North East Thames, while having a district appointed forensic psychiatrist, did not involve him in the planning process, and are the only Thames Region without a regional forensic psychiatrist. The Region decided on small subregional units rather than a single RSU. How the secure units that are being planned at Runwell, Hackney and Claybury Hospitals will function without such a forensic

*This article is based on a paper presented at the 4th Symposium on Regional Secure Units held at Chester in March 1983. (Amendments made in June 1983.) input is uncertain. The only unit with a forensic psychiatrist was to have been built at Friern Hospital, but plans have been held up as the future of this hospital is uncertain.

Devon and Cornwall (South Western Region) completed the building of a 30-bed RSU at Langdon Mental Handicap Hospital in Dawlish in July, 1982. The forensic psychiatrist, who was not appointed until late 1981, noted design problems which require building alterations. There is no interim secure unit, but it is hoped to appoint staff and open 10 beds after the alterations are completed this summer.

Trent completed the large 60-bed RSU in January 1982 at Towers Hospital, Leicester. An interim secure unit was opened in that hospital in January 1982, but only two-thirds of its 15 beds are in use due to difficulties in nurse recruitment. Because of this the RSU is still empty, although it is hoped to open 15 beds this summer when the interim secure until will close.

The rest of the Regions had regional forensic psychiatrists on planning teams. The second RSU in South Western Region is the 30-bed unit at Glenside Hospital, Bristol. The Stage 1 planning submission is about to be sent to the DHSS. It is hoped that the unit will open in 1986. Although the forensic psychiatrist currently runs open beds, there is no interim secure unit.

In Yorkshire Region a 48-bed RSU is currently being built at Fieldhead Mental Handicap Hospital, Wakefield. It is hoped to open the unit in May 1984. The future of the recently opened 24-bed interim secure unit (Tuke Ward at Stanley Royd Hospital, Wakefield) will be uncertain when the RSU opens. The RSU will provide a service for most, but not all, of the Region, especially relating to the four already operating special care units in Ilkley, Huddersfield, York and Beverley near Hull.

In Mersey Region there are two interim secure units, one is at Parkside Hospital in Cheshire, and the second (run by the forensic services) is a 24-bed unit at Rainhill Hospital, Prescot. The interim facilities will close when the 50-bed RSU at Rainhill Hospital opens 30 beds this summer.

North West Region currently has three interim secure units, two wards at Prestwich Hospital, Manchester and the third in Whittingham Hospital, Preston. It is now felt that plans drawn up in 1976 are not necessarily applicable to 1983, particularly with the experience of running the interim secure unit at Prestwich Hospital. A plan to convert a building at Prestwich Hospital into the permanent RSU has now 
been altered, even though building work is currently taking place. This will be used temporarily from $1985-88 / 9$, while the interim secure unit at Prestwich Hospital is upgraded. This will then become the 60-bed RSU. An adolescent secure unit has been built on the same hospital site. It is not yet open and a forensic psychiatrist has not yet been appointed.

West Midlands will begin building the largest RSU on the Rubery Hospital complex site, Birmingham. The future of the interim secure units at Warwick and Bromsgrove will be uncertain when the 100-bed RSU opens in 1985.

East Anglia was one of the last Regions to set up a planning team for regional secure units. The site was eventually agreed at St Andrews Hospital, Norwich. Because of the lack of secure facilities in the region and the failure to open an interim secure unit, planning has been extremely rapid. The unit should be completed in November 1983, and 10 of the 36 beds will be opened in May 1984 if enough nurses are recruited.

North West Thames, one of the slower regions, only set up an RSU project team in 1982, but the Stage 1 planning permission has recently been accepted by the DHSS and it is hoped to open the 40-bed unit at St Bernards Hospital, Ealing in 1986. The Region are proposing an RSU with two satellite secure units, and planning has already begun for one of them, which will be located at Leavesden Mental Handicap Hospital. A 14-bed interim secure unit at St Bernards Hospital is due to open in the summer of this year, but will close when the RSU opens.

South East Thames has proposed the most complex solution-a 30-bed RSU at the Bethlem Hospital, without a catchment population of its own, and four 15-bed area secure clinics at Bexley, Cane Hill, Hellingley and Oakwood Hospitals, each with a sub-regional catchment population. All are currently being built and it is hoped to open the units in mid-1984.

South West Thames are just about to, or have recently, sent the Stage 2 planning submission for their 25-bed RSU to the DHSS. The site is to be at Netherne Hospital, and it is hoped that the unit will open in 1987. Although a small unit with reference to the regional population of over three and a half million, capital forensic money has been used to convert units in every psychiatric hospital in the region to produce over $\mathbf{6 0 0}$ close supervision beds. These will act as a support for the RSU.

In the Wessex Region the single interim secure unit at Knowle Hospital will close when the RSU opens on the hospital site in late 1984 early 1985 . The Stage 2 planning submission has recently been accepted by the DHSS for the conversion of an existing hospital building into the 28-bed RSU.

\section{Future plans}

Most of the Regions have now made firm decisions on their secure services. However, because of the eccentric siting of the RSUs in Northern and Trent Regions, it may be that, like South Western Region, further secure units will be planned and built if the necessary finance is available. Trent Region is at present debating whether there should now be a second RSU or one to two satellite secure units.

\section{RSU design}

Each RSU has been designed specifically to provide a pleasant exterior and interior environment. Most are purpose built rather than adapted buildings. Security will not be obvious and the buildings are intended to blend into the surroundings and general environment. The high nurse to patient ratio is in fact the main source of security. Any extra security will be in the structure of the building itself (for example, reinforced window frames and non-breakable glass) rather than, if present, external security fencing. Most of the units are of large enough size to contain an outside patient area within the structure of the building. The secure shell is entered by means of an electrically operated double door air lock system, although at the other end of the spectrum the Wessex RSU will have two wards each with a single entry door under lock and key. In some RSUs the whole unit is within the secure shell, while others have administration outside the security air-lock system. The Mersey RSU is flexible enough to run a pre-discharge ward outside central security. The most common approach is to have an admission/assessment unit with secure rooms, an intermediate/continuing treatment unit and a predischarge/lower security unit. Most have single bedrooms, although apart from the admission ward, many have some beds in dormitory areas. Also within the RSU there is variation in the amount of space allocated to occupational therapy/recreational and educational space. The larger units will contain a multi-purpose hall, gymnasium, hairdresser and shop.

\section{RSU staffing}

The staffing approach varies from Region to Region. In part the staffing proposals reflect the size and design of the unit, but also the general philosophy of the forensic service. Some units, perhaps because of combinations of site and philosophy, will have clinical staff who are unit-bound with the danger of becoming professionally isolated and inward looking, running what can be called a secure unit service. Others intend to pursue a comprehensive approach with the RSU forming part of a more general forensic service. Here all clinical staff work not only in the RSU but also in the community, seeing out-patients and working for the courts and in prisons. Some Regions have gone so far as to displace the RSU as the only service base. Both Mersey and South West Thames will have community bases for patient followup, teaching and research.

The mean number of consultant forensic psychiatrists per population served will be just over one forensic psychiatrist per million (with a range of 0.5-1.8 per million). All Regions will have various brands of senior registrars, and most, but not all, with have registrars from rotational pools. While all 
units will have nursing officers, some will have senior nursing officers. The units will run on nurse patient ratios ranging from 1.5:1 to 2.8:1 with a mean of around 2:1. Part of this variation is a reflection of the different shift systems. Most RSUs will appoint principal psychologists to head the establishment, but staffing plans vary from a single psychologist post to complements as large as six. Occupations have been approached in various ways from the occupational therapy model to rehabilitation managers, technical instructors, gymnasts and even physiotherapists.

\section{Research}

Part of the remit for RSUs, according to Butler, was as a centre for research. Buildings such as the Bethlem RSU and Trent RSU are well endowed for such a function. It is important that each Region pursues this course in order to make firmer the academic base of forensic psychiatry. There is an RSU research unit based in Birmingham and they are about to commence a detailed comparative clinical research study on seven regional secure units.

Conclusions

The rate of progress around the country and the models chosen are various. Those Regions with little forensic psychiatry involvement in planning have run into problems with the structure, site of unit, and its function as a base for a forensic service. Other Regions have been led by the forensic psychiatrist into adopting differing RSU and service models. Over the next two years there will be dramatic changes. Of the 717 planned permanent places (excluding mental impairment and adolescent units), 120 were completed by March 1983, although only 20 beds were open. By March 1984 around 344 beds will be completed with between 80 to 110 functioning beds, and by late 1984, with further RSUs opening, we may have well over 200 staffed RSU beds. We are now reaching the situation whereby the limiting factor is not the building of RSUs, but the staff (especially nursing) to run them. The problem is not only in recruitment. Recently a number of Regions have attempted to cut back their share of the revenue allocation, putting not only the security of these units at risk but their whole philosophy. It will be interesting to see how the picture develops.

The views, ideas and proposals expressed in this paper are not necessarily those of the DHSS.

\title{
What Do Psychiatrists Understand by Formulation?
}

\author{
A Survey of Clinicians in a Group of Hospitals in London \\ Julie A. Hollyman, Clinical Research and Honorary Senior Registrar and LoIC Hemsi, Consultant Psychiatrist, St
} George's Hospital Medical School, London SW17

Following the taking of a psychiatric history and the examination of the mental state, it is standard practice to prepare a formulation (Institute of Psychiatry, 1973; Slater and Roth, 1977; Royal College of Psychiatrists, 1979; Garrick and Stotland, 1982). Indeed, the concept of formulation is central to the psychiatrist's approach.

The authors' renewed interest in the formulation arose from a discussion of the experience of one of them during the clinical examination for the MRCPsych in 1981. She was disconcerted to find that she and the examiner differed substantially as to the meaning of the term and what was to be included in the formulation. This was thought not to be unique, and it seemed probable that the term was being given different interpretations. An examination of the literature extant in the autumn of 1981 confirmed that view.

In April 1979, the Association of Psychiatrists in Training (APIT), in an open letter to the Bulletin criticizing the MRCPsych examination, questioned whether examiners agree among themselves about the notion of formulation. That letter provoked some correspondence, but the College did not itself make a response.
In June 1979, the 'Scribe's Column' in the Bulletin outlined four views on formulation (including APIT's own) and concluded that a diagnostic formulation is a 'summary of the relevant genetic, constitutional and personality factors and their interaction with aetiological factors, taking into account the patient's life situation, together with a provisional diagnosis and plan of treatment.' This paper was reprinted in Handbook for Inceptors and Trainees in Psychiatry, alongside another article entitled 'The MRCPsych Examination' where the formulation was described as 'a summary of the essential features of the history, mental state and physical examination.'

One might reasonably expect to find more guidance in standard textbooks. In fact, if there is reference at all to formulation, it is cursory and opinion is not uniform. Some authors (Myre Sim, 1974; Anderson and Trethowan, 1973; Hill et al, 1979) do not consider the question at all. Amongst authors who do consider formulation, two main schools of thought appear. On one side are those (Institute of Psychiatry, 1973; Priest and Steinert, 1977; Slater and Roth, 1977; Curran et al, 1980) who tend to the view that the 